\title{
Modification and Development of a Blow Molding Machine
}

\author{
Bassam A. Al-Helou \\ Faculty of Engineering Technology, Zarqa University, Zarqa, Jordan \\ Email: heloub@hotmail.com
}

Received January 15, 2012; revised January 30, 2012; accepted February 10, 2012

\begin{abstract}
This study is based on the modification and development of a two-liter plastic container blow molding machine into a five-liter one provided with a translucent view stripe. This study considers some objectives including reducing the total cost, increasing the amount of plastic recovery, and raising the desired plastic materials. Proper designs were prepared and directly applied on spot. Tangible results were obtained. Among others, the modification of some components of the machine, e.g. the extruder, has led to the possible re-use of the milled (recovery) and extra material from the manufacturing processes. That was also conducive to an effective reduction in the cost of production to $50 \%$ in some cases. Prior to its modification, this old machine was used to produce polyvinyl chloride (PVC) containers that have become prohibited these days for their damaging effect on man's life. For now, and after modification, it has become possible to use High Density Polyethylene (HDPE) material, a fact that has improved labor conditions, too.
\end{abstract}

Keywords: Blow Molding Machines; Translucent View Stripe; Container; Extruder

\section{Introduction}

The idea was that in stead of purchasing a costly new machine, the old one can be modified. In case of failure, however, the modification cost would only be commensurate to a tiny amount of a new machine's price. The study relies especially on the development of the single extruder and production of the container with translucent view strip.

The single extruders are used to generate a continuous flow of molten polymer in many industrial polymer processes, like blow molding [1-3]. The extruder essentially consists of an Archimedean screw rotating within a stationary barrel. A die is attached to the output end of the extruder to shape the melt into the desired form. The output characteristics of the extruder can be expressed as sum of two components: 1) drag flow, this is the positive component of the output and is related to the motion of the screw relative to the barrel; 2) pressure flow, this is normally the negative component of the output and is related to the pressure generated at the outlet end of the extruder, this pressure being required to force the melted material through the shaping die [1].

It is normal practice to divide the screws into 3 zones. The function of feed zone is to collect powder from the feed hopper and transport them up the screw channel. At the same time, the powders should begin heat up and compact and build up pressure as they advance towards screw tip (die end). Powders should not accumulate in the screws channel for effective pumping. They should rather show high degree of slippage on the screw channel surface and low degree of sleeping on the barrel. The compression zone or transition zone could be of two type, 1) gradual transition, long compression zone, 2) sudden transition, short compression zone. The screws with sudden transition are required for plastic material with a narrow melting range such as nylon and screws with gradual transition are material with wide melting range. In the melting zone, the polymer melt is brought to correct consistency and pressure required for extrusion. The melt should be pumped to the die at a constant rate, consistency and pressure. Theses properties may vary from point to point but when measured to a particular point should not change with time. Higher melting pressure is required in the metering zone in order to mix melted material to give it constant properties through out hence obtain smooth extrudate [4-6].

The developed extruder has an L (length)/D (diameter) ratio of 30 , with $\mathrm{D}=30 \mathrm{~mm}$. The feed section of the screw has a channel depth of $3 \mathrm{~mm}$, while in the metering section $\mathrm{H}=2.5 \mathrm{~mm}$. The axial length of the feed, compression and metering sections (L1, L2 and L3) is the same and equal to $300 \mathrm{~mm}$. The flight helix angle is constant and equal to $17.65^{\circ}$. The modification was introduced to the feeding section by $2 \mathrm{~mm}$ increase in its drilling depth so that the large-sized crushed material be 
incorporated.

The extruder and die are usually jointed using a ring or a breaker plate. A breaker plate is a disc that has a multitude of holes through it to allow the passage of the mesh between the extruder and the die. A breaker plate is normally used to support filtration meshes. It has been argued that the melt flows in helical fashion, due to the rotation of the screw, as it exits the screw [7-9]; the breaker plate causes this helical motion to become axial. A ring is used where the polymer being processed is heat sensitive and degradation may occur due to increased residence time at the inlet and outlet of the breaker plate.

Another modification of this study relates generally to blow molding machines and more particularly to a blow molding apparatus for producing a container with a translucent view stripe on the mold part line on the container.

Plastic containers, such as motor oil containers, are generally made of an opaque colored plastic resin to provide product identification for consumers. A disadvantage of opaque containers is that it is not possible to visually monitor the level of the container contents. One solution for ascertaining the level of contents in an opaque plastic container is to form the container with a vertical stripe of a translucent plastic resin in the side wall of the container. In this Study the opaque containers are provided with translucent plastic view stripes on the mold part lines on the containers. The location of the view stripe on the container part lines enables the manufacture of containers with view stripes confined to the side wall. This avoids the unusual look of having view stripes running through the top and bottom of the container where, in many cases, where such stripes were not available $[10,11]$.

\section{Translucent View Strip Line}

The objective of this project to provide an improved blow molded container with a view stripe on the part line and apparatus for making such a container on existing blow molding machinery, such as reciprocating screw type blow molding machines.

The apparatus of this study utilizes a multi-cavity die head assembly for producing multiple parisons each having a translucent view stripe through the wall of the parison. A manifold assembly is used to supply a primary and a secondary resin to each of the die heads. A primary reciprocating screw extruder is used for extruding a primary resin which is pigmented and opaque. A secondary reciprocating screw extruder is used for extruding a secondary resin of the same or similar type as the primary resin only non-pigmented such that it is translucent.

The primary and secondary resins are fed into the interior cavity of each die head at locations diametrically opposite each other. The mandrel sleeve is equipped with a diverter sleeve which divides the flow of the primary resin into two flow streams flowing in opposite directions around the mandrel sleeve. The diverter also directs the flow from a horizontal direction to a vertically downward direction. As the primary resin flows downward and around the mandrel sleeve, a vertical gap is formed between the two flows of primary resin at the opposite side of the mandrel sleeve from where the primary resin is fed into the die head.

A secondary non-pigmented resin is inserted into the die head and directed downward into the gap between the primary resin forming a weld of the primary resin. As a result, a tubular parison is created having a vertical stripe of a translucent resin in the wall of the parison.

This tubular parison is then ejected through an annular outlet at the bottom of the die head. The blow mold is positioned below the die head outlet such that the mold halves can then be closed upon the parison. The mold halves are oriented relative to the parison such that the parting line between the mold halves is aligned with the view stripe of the parison. When blow air is injected into the mold to mold the parison to the desired shape, the view stripe is blown into engagement with the parting line, thereby forming a container in which the view stripe is on the parting line.

The advantage of placing the view stripe on the parting line of the mold halves is that the view stripe length can be limited to the side wall of the container. If not located at the parting line, the view stripe will continue across the top and bottom walls of the container to the center of the top and bottom walls.

In producing a bottle in which the fill opening is off center, the mold is shifted to one side after closing upon the parison. The blow pin is then extended into the fill opening of the bottle and the blow air is injected into the bottle forcing the parison against the inner wall of the mold cavity to produce a bottle having a shape of the mold cavity.

A container is thus formed which includes a vertical view stripe of a translucent resin through the side wall of the container along the parting line of the two mold halves. By locating the view stripe on the mold parting line, the view stripe of the side wall can, in some cases, end up as flash extending above the side wall which is removed so that the view stripe conveniently ends at the upper end of the side wall. The molds can be oriented to produce the view stripe on either parting line of the container.

It is within the purview of this study to use any suitable blow moldable plastic resin that can be utilized in both opaque and natural or translucent forms. In any blow molded container produced by this Study, the two plastic resins must be compatible to join together at the parison weld line. In one form, high density polyethylene 
for both the opaque and translucent resins provides a container with an excellent view stripe through which the container contents can be readily ascertained.

\section{Technical Description}

The drawing of this study include a die head manifold assembly indicated generally at 16 in Figure 1 which illustrates two side by side die head units, 18 and 20, of a multi-cavity die head assembly.

A primary reciprocating screw extruder (not shown) is attached to the primary plastic resin inlet 22 . The primary extruder is used to extrude a pigmented plastic resin into the die head to form a parison. The pigmented plastic resin flows through conduit 24 to a horizontal primary flow channel 26 which runs longitudinally through the manifold assembly to allow the primary resin to flow to each end of the manifold.

Located at prescribed intervals along the flow channel 26 are vertical conduits 28 which direct the primary resin upward to horizontally positioned primary sleeves 30 . Sleeves 30 are perpendicular to flow channel 26 and direct the flow of the primary resin to each of the die head units such as units 18 and 20. An adjustable choke screw 32 is operable to adjust the position of a flow plug 34 Figure 2 at the outer end of each primary sleeve 30 to balance the flow of the primary resin to each die head.

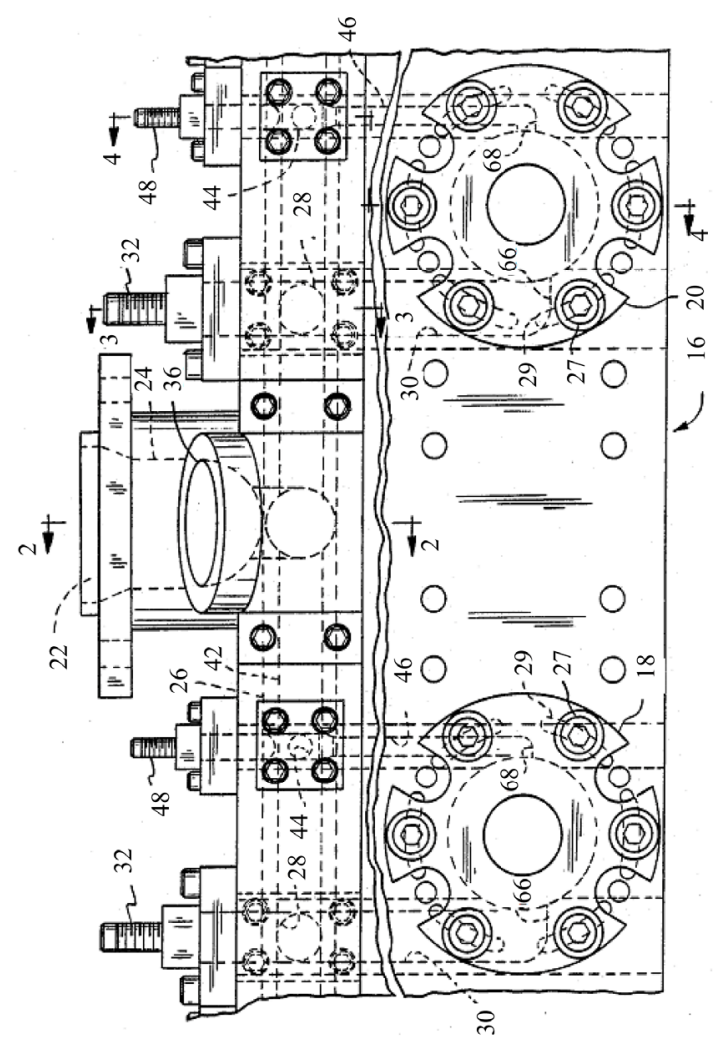

Figure 1. The plan view of a portion of the multiple die head and manifold assembly [12].

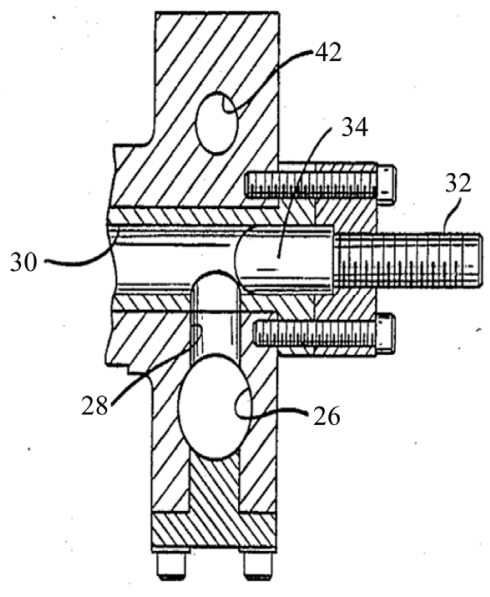

Figure 2. A sectional view of the primary sleeve and flow adjustment plug as seen from substantially the line 3-3 of Figure 1.

A secondary natural resin, which is not pigmented, is extruded by a second reciprocating screw extruder (not shown) positioned above the primary extruder and attached to a secondary resin inlet 36 Figure 3 . The nonpigmented resin, which is used to form the view stripe in the parison, flows through a conduit 40 to a horizontally positioned secondary flow channel 42 which is spaced above the primary flow channel 26 . The secondary flow channel 42 allows the non-pigmented resin to flow to each end of the manifold assembly.

At prescribed intervals along the secondary flow channel, vertical conduits 44 Figure 1 direct the non-pigmented resin downward to horizontally positioned secondary flow sleeves 46 which direct the flow of the resin to the cavity in each die head unit. At the outer end of each secondary flow sleeve 46, an adjustable choke screw 48 Figure 4 and a flow plug 50 balance the flow of the secondary resin to each die head.

The die head manifold assembly thus supplies both the pigmented primary and the non-pigmented secondary resins to each die head cavity in the multi-cavity blow molding machine. During automatic operation of the machine, an electrical signal is simultaneously given to both the primary and secondary extruders. The primary extruder is hydraulically powered forward pushing a shot of molten pigmented plastic resin into the die head assembly. The secondary extruder is also hydraulically powered for pushing a shot of molten non-pigmented plastic resin of the same type as used in the primary extruder. This non-pigmented, or translucent resin is injected into the pigmented parison stream as it moves through the die head cavity as described below [12].

As seen in Figure 1, the primary sleeve 30 and secondary sleeve 46 direct the primary and secondary resins respectively to diametrically opposite sides of the die head cavities. 


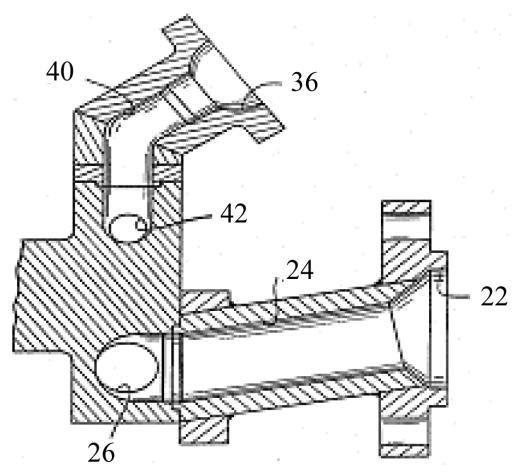

Figure 3. A sectional view of the primary and secondary resin inlets to the manifold as seen from substantially the line 2-2 of Figure 1.

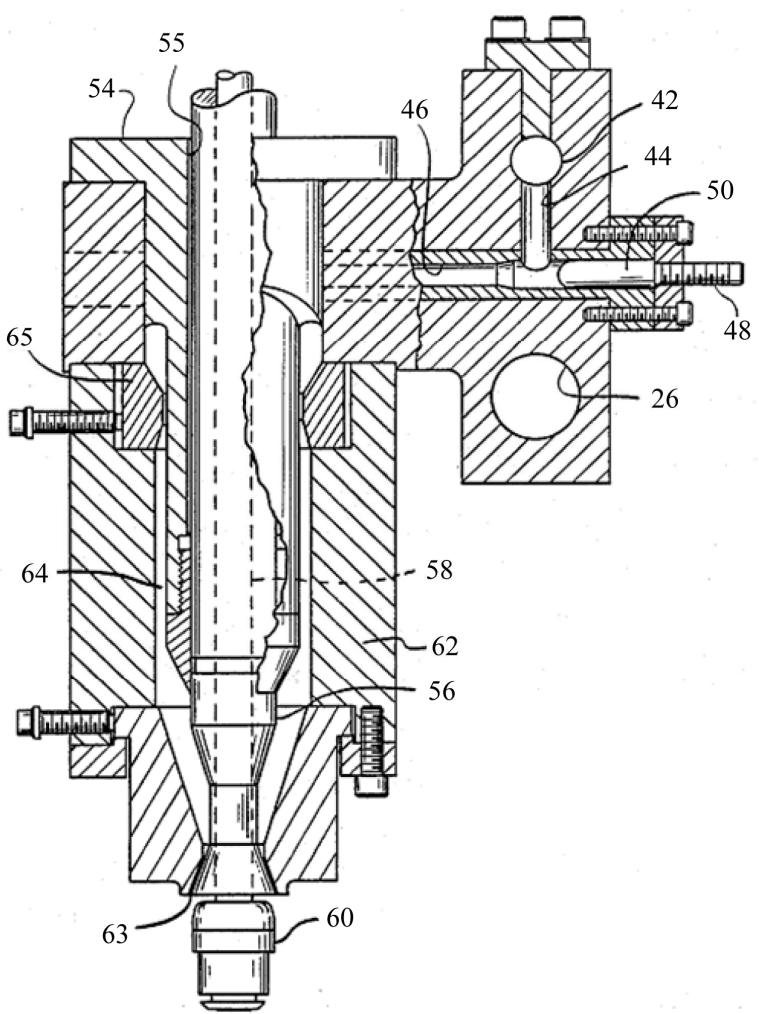

Figure 4. A vertical section view of the die head and the secondary sleeve and flow adjustment plug as seen from substantially the line 4-4 of Figure 1.

The die head cavity, as shown in Figure 4, is formed by a cylindrical mandrel sleeve 54 which has an axial bore 55 there through. A mandrel 56 extends through the bore 55 . The mandrel 56 in turn has an air conduit 58 extending axially there through to a conventional blow pin 60 projecting below the die head. A die body 62 is supported in spaced relation around the mandrel sleeve 54 and mandrel 56 so as to define therewith an annular die head cavity 64 having an annular outlet orifice 63 . An adjustment ring 65 is used to balance internal pressures within the die head cavities 64 .
The primary resin flows from the primary sleeve 30 through an inlet orifice 66 into the cavity 64. Likewise, the secondary resin flows through the secondary flow sleeve 46 through an inlet orifice 68 into the cavity 64 .

The mandrel sleeve 54, illustrated in Figure 5, is used to combine the primary and secondary resins into a single parison flowing downward through the cavity 64 .

The mandrel 54 includes a radially outward extending diverter segment 70 . The diverter segment 70 has a surface 71 which faces axially downward toward the annular outlet orifice. The surface 71 has two downwardly curved and inclined sections 73 which terminate in horizontally spaced edges 72 which define a gap 77 there between which is diametrically opposite primary inlet 66 and axially below secondary inlet 68 . Surface 71 defines an accurate flow path for the primary resin. As the primary resin flows through inlet orifice 66 into the cavity 64 , the flow of the resin is divided in two streams which flow circumferentially around the mandrel sleeve in both directions from the inlet orifice 66 .

The surface 71 directs the flow of the primary resin from the horizontal flow direction in sleeve 30 to a vertical flow direction downward in cavity 64 . The divided flow streams of the primary resin flow around the mandrel sleeve to a position at the opposite side of the mandrel sleeve from the inlet orifice 66 to positions below the edges 72 .

The diverter 70 includes a generally $\mathrm{V}$-shaped passage 74, shown in Figure 6, between the two edges 72. The $\mathrm{V}$-shaped passage 74 is shaped, in cross section, so that it has a wide portion 75 Figure 7 located radically, inwardly of the outer surface of slot 74 forming a substantially T-shaped section. Likewise, the passage 74 Figure 6 also has a wider inlet portion 79 at its upper end which

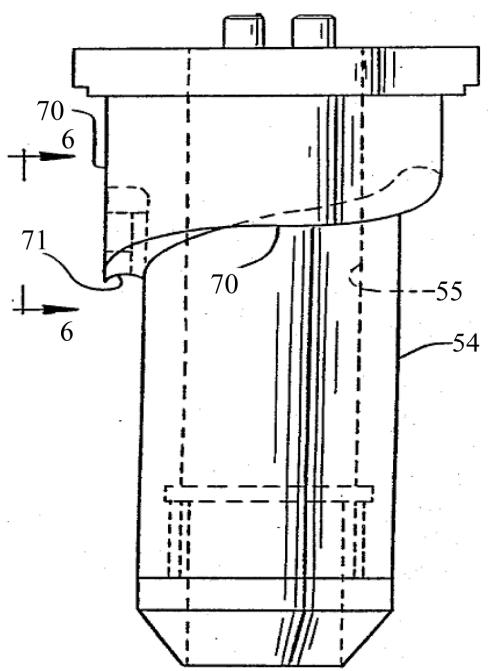

Figure 5. A side view of the mandrel sleeve and primary resin flow diverter in a position as viewed from the left in Figure 4. 


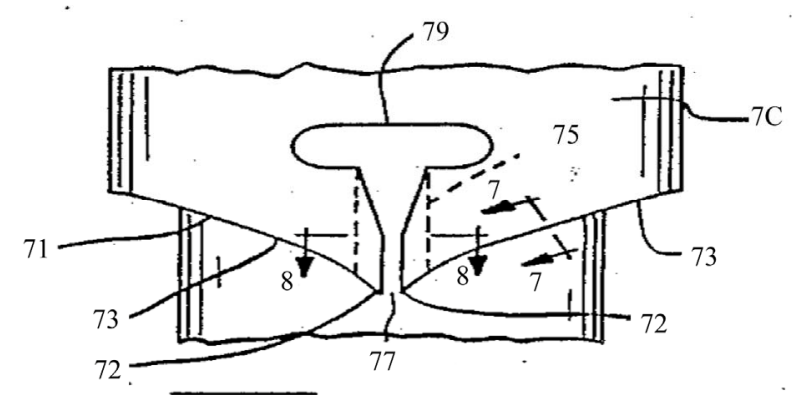

Figure 6. A fragmentary side view of the mandrel sleeve as seen substantially in the direction of arrows 6-6 of Figure 5.

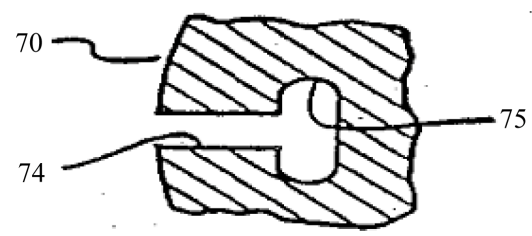

Figure 7. A fragmentary sectional view as seen from substantially the line 8-8 of Figure 6.

is in communication with secondary resin inlet orifice 68 . Passage 74 defines a conduit for the flow of the secondary resin from the sleeve 46 to the die head cavity 64 and the large inlet insures that the passage 74 will be filled at all times.

As the secondary resin flows through orifice 68 into the passage 74 , the resin is directed downward through gap 77 past the edges 72 into the flow of the primary resin at the point where the divided flow streams of primary resin flow toward each other below the gap 77 . In this manner, the secondary non-pigmented resin is joined into the tubular parison of primary resin so as to form the weld line between the divided primary resin flow streams.

The tubular parison 82 has an inner surface 83 and an outer surface 85 Figure 8. To form a clearly defined view stripe with sharp edges, the circumferential width of the view stripe at the inner surface 83 must be equal to or greater than the view stripe width at the outer surface 85 . To assure that the inner surface of the view stripe is wider than the outer surface, the passage 74 is shown as being substantially T-shaped in Figure 7. However, it is to be understood that passage 74 can be of other shapes in which the inner surface is wider than the outer surface [12].

If passage 74 has a constant width, the inner surface of the view stripe would be narrower than the outer surface. This is because the primary plastic flowing around the mandrel sleeve on the inner surface has a shorter distance to travel than the plastic of the outer surface. Therefore, if the passage 74 is not wider at this inner surface, the resulting view stripe will be narrower at the inner surface than at the outer surface resulting in clouded edges of the

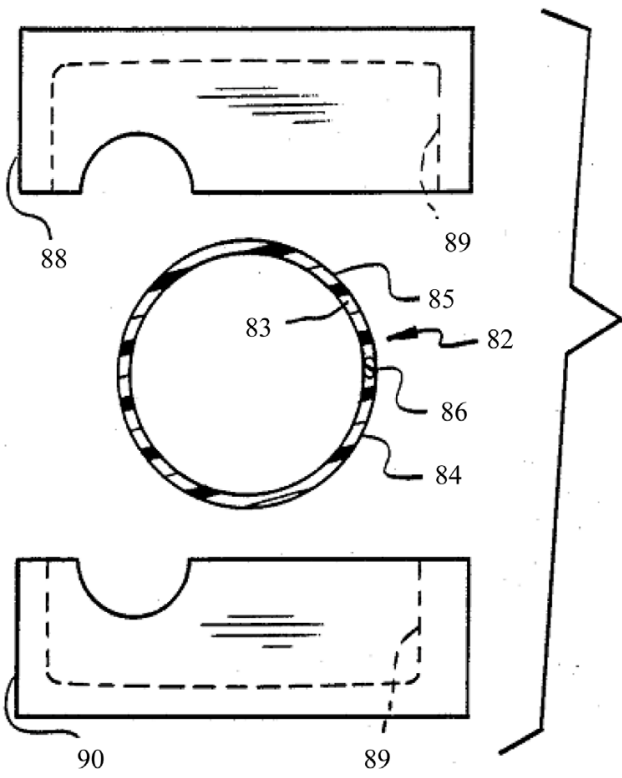

Figure 8. A sectional view of the parison shown in relation to the mold halves, the parison having been formed with the view stripe on the right hand side of the parison as viewed in this figure.

view stripe. The clouded or hazy edges are due to the edges of the opaque side wall of the container being visible through the view stripe.

Another important factor in producing a view stripe with clearly defined edges is proper alignment of the inner and outer surfaces of the stripe so that neither of the opaque edges is visible when looking into the container through the view stripe. If the passage 74 is not positioned diametrically opposite the primary resin inlet 66 , the outer surface of the view stripe will be offset from the inner surface. This results in the view stripe having one well defined edge and one clouded edge.

The well defined edge will be the edge which is closest to the primary resin inlet 66 . To provide for proper alignment, the mandrel sleeve 54 can be rotated to adjust the position of the passage 74 . The upper portion 79 of passage 74 is in communication with the secondary inlet 68 and is circumferentially wider than the remainder of passage 74 to allow for rotation of the mandrel sleeve and maintain communication with the resin inlet 68 . The mandrel sleeve 54 is mounted to the die body 62 by bolts 27 Figure 1. Slots 29 in the die body 62 accommodate the rotation of the mandrel sleeve.

A cross section of the diverter segment 70 is shown in Figure 9 to illustrate the upwardly concave shape of the surface 71 of the diverter 70 .

The simultaneous operation of the primary and secondary extruders forces the molten plastic resins to flow into the die head cavity 64 forming a tubular parison which flows through the annular outlet orifice 80 at the bottom of the die head. The tubular parison is formed of 


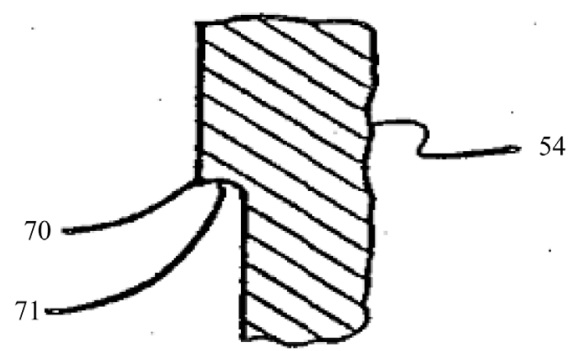

Figure 9. A fragmentary sectional view as seen from substantially the line 7-7 in Figure 6.

the pigmented primary resin with a longitudinal stripe of the secondary natural resin extending radially through the parison wall so as to form a view stripe in the parison. The parison, as it flows out of the outlet 80 , encircles the blow pin 60 extending from the lower end of the mandrel 54.

Figure 8 illustrates a parison 82 formed of the primary resin 84 with a narrow longitudinal section comprised of the secondary natural resin 86 which extends radially through the parison wall. When the parison 82 has been extruded from the die head of a sufficient length to form a blow molded container, the primary and secondary extruders have completed their forward strokes, thereby discontinuing the discharge of the plastic from the outlet orifice 80 . The two mold halves 88 and 90, shown in Figure 8 in the open position, are moved together enclosing the parison in the mold cavity 89 . The orientation of the mold halves relative to the view stripe 86 in the parison results in the production of the final container in which the view stripe 86 is formed along the parting line between the two mold halves 88 and 90 .

Figures 10-12 illustrate the parison and the mold after the mold has been closed. In Figure 10, a section of flash 92 is formed between the two mold halves above the mold cavity 89 as the mold halves are closed upon the parison. Because the view stripe is located on the mold parting line, the outer vertical edge of the flash 92 includes the secondary, non-pigmented resin 86 which forms the view stripe.

In the final container, the view stripe will only extend to the point 93 at the outer vertical edge of the flash.

The extension of the view stripe along the top and bottom walls can thus be controlled as a result of locating the view stripe on the parting line.

The mold is then shifted to one side such that the neck portion 91 of the mold cavity is in alignment with the blow pin 60 Figure 11. After the mold is moved into this position, the blow pin is extended downward into the mold cavity so as to form the neck portion of the container Figure 12. Blow air is then injected through the blow pin into the interior of the mold cavity forcing the parison outwardly against the interior surface of the mold cavity thereby forming the finished container 98 as shown

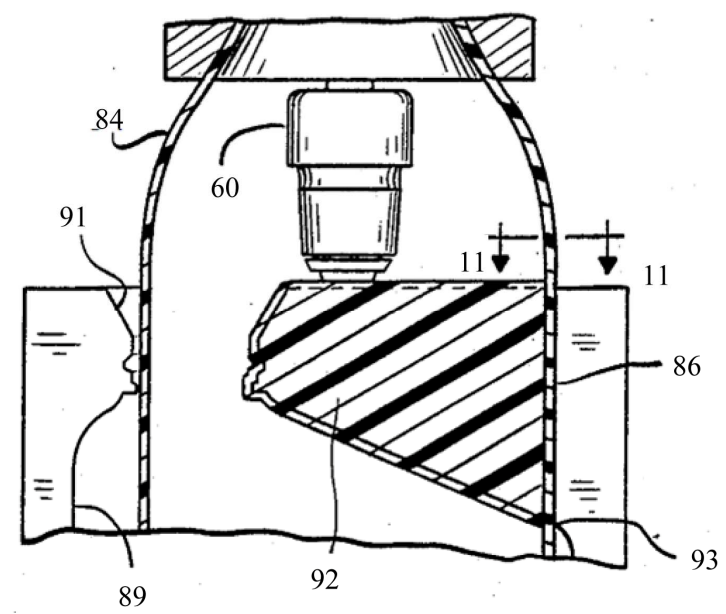

Figure 10. A sectional view of the parison after closure of the mold halves, also viewed with the view stripe to the right hand side of the parison.

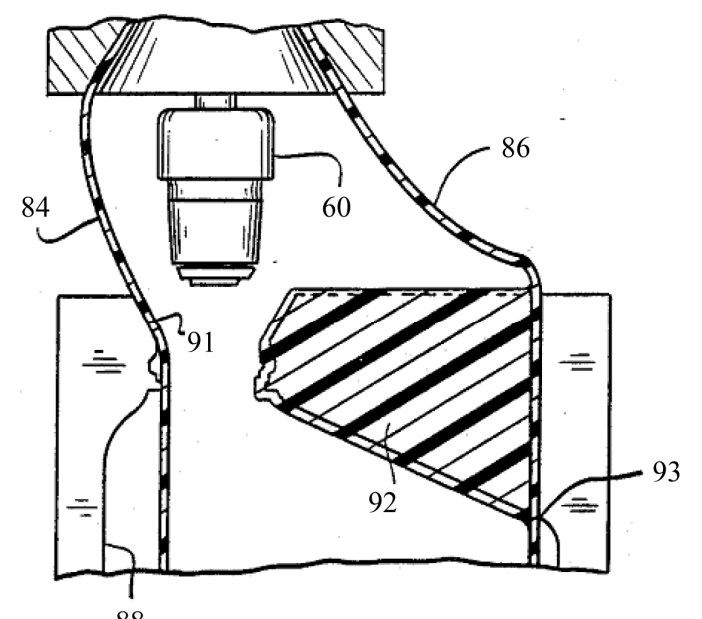

Figure 11. A sectional view of the parison similar to Figure 11 with the mold shifted to position the blow pin above the container neck opening.

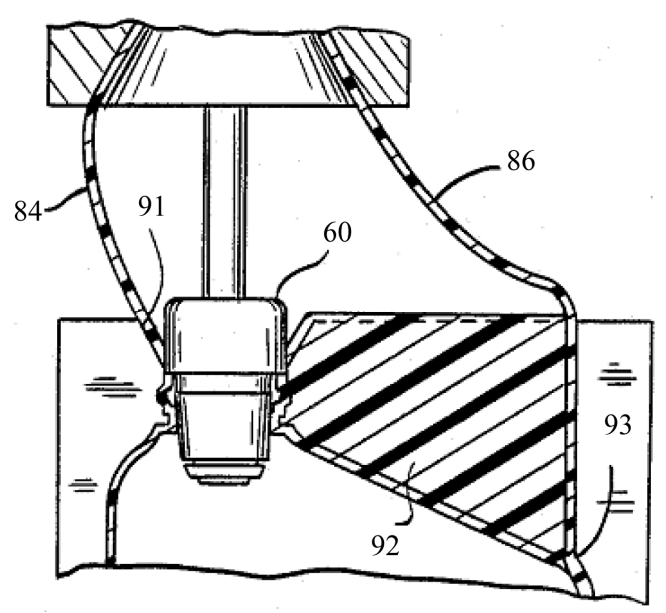

Figure 12. A sectional view similar to Figure 12 with the blow pin extended into the container neck opening. 


\section{in Figure 13.}

Figure 14 is a cross section of a portion of the parison showing the view stripe 86 . To provide a view stripe having a uniform width, a uniform temperature in the shot of resin used to form the view stripe is maintained.

The relative temperatures and viscosities of the primary and secondary resins are also important in controlling the view stripe width and sectional shape. A higher viscosity for the secondary resin than the primary resin results in a view stripe of a generally elliptical shape as shown in Figure 14. The pressure forcing the parison through the outlet orifice 63 causes the higher viscosity secondary resin to bulge outward forming the elliptical shape. The lower viscosity primary resin flows around the secondary resin at the inner and outer surfaces forming a vertical edge for the view stripe. In a preferred em-

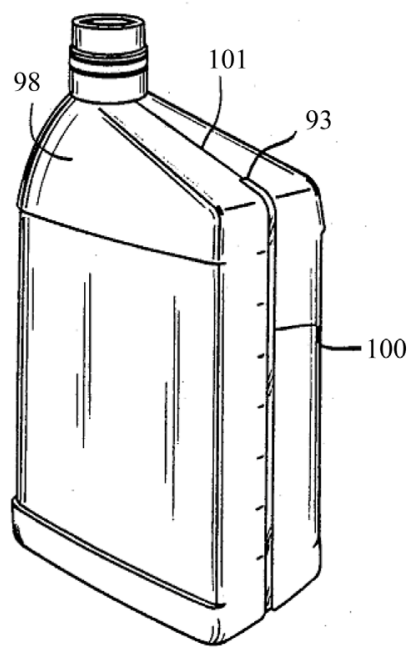

Figure 13. A perspective view of the finished container with a view stripe in the container side wall at the mold parting line.

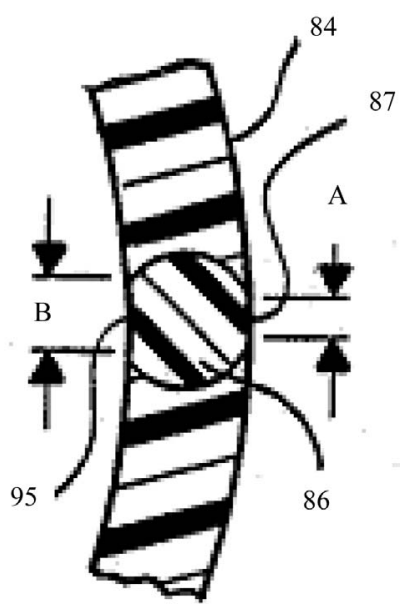

Figure 14. An enlarged sectional view of a portion of the parison as seen from substantially the line 11-11 of Figure 10 illustrating the view stripe in the parison wall. bodiment, the translucent resin is at a higher temperature than the opaque resin to minimize the intrusion of the translucent resin into the opaque resin. What is shown in Figure 14 is only illustrative. Other satisfactory view stripes can be formed with less translucent resin intruding into the opaque resin than that shown in Figure 14.

As discussed previously, the dimension A of the outer surface of the view stripe 87 must be smaller than the dimension B of the inner surface of the view stripe 95 to produce well defined edges of the view stripe. In addition, the outer surface 87 must be aligned radially outward from the inner surface 95 .

Container 98 is comprised primarily of an opaque plastic resin with a longitudinal view stripe 100 along the parting line 101 between the two mold halves. The view stripe enables visual monitoring of the level of the contents of the container.

From the above description it is seen that this Study provides a container 98 with a translucent view stripe 100 extending along the parting line of the container. The view stripe 100 is a clearly defined vertical line on the container 98 and is it not clouded by the opaque plastic from which the container body is molded [12].

\section{Modified Parts}

A few remarks should be made to articulate the work done in the process of the machine modification and development. Among others:

- Replacing the PVC by HDPE.

- Alteration of the machine's production system from a 2 liter to 5 liter capacity.

- Deeper extruder drilling to $2 \mathrm{~mm}$ so that hopper can absorb large-sized crushed material. The increase in drilling is conducive to an increase in production. Practical observation proved a $25 \%$ increase of production, thanks to the extra raw materials absorbed by the hopper.

- Modification of Blow head to operate from a static to a mobile system; i.e. moving in all directions; up and down, right and left, back and front.

- Enlargement of the station aperture from $20 \mathrm{~cm}$ to 50 $\mathrm{cm}$ to enable the machine absorb 5-liter containers.

- Producing containers with translucent view stripes which were missing in this technology, and using crushed materials that were not used before.

- Canceling the formerly fan system of cooling which was operated in producing PVC plastic containers.

\section{Result and Analysis}

This clearly shows that the out-dated machine has become a reliable, productive machine. The idea was that in stead of purchasing a costly new machine, the old one can be modified. In case of failure, however, the modifi- 
cation cost would only be commensurate to a tiny amount of a new machine's price. The factory's production capacity of this kind of containers, after the machine development, was apparently felt. Namely, the machine has become capable for larger production in 5-liter containers, and with the development of the station, it became apt for extension to $50 \mathrm{~cm}$ (formerly $20 \mathrm{~cm}$ ), and with the translucent view stripe added to the modified machine, the produce quality has improved. In fact, the factory missed this kind of production in the past.

Despite the heavy demand of the local market, the factory couldn't deliver for lack of capability. Now, the situation is completely different.

Figures 15-16 show the machine's new shape after modification, while Figures 17-18 show the newly produced 5-litre containers with the translucent view strip. Figures 19-20 show the top part of the machine before and after its modification. Now the machine's upper part, including the extruder, can move up and down, right and left sides.

Experiment has shown that in the event of adding more than $50 \%$ of the crushed material to the light-colored containers in production, the quality of the product shall be affected. Hence, the mix percentage should not exceed $50 \%$, but in the case of opaque colored material, no such effect was observed even if the mix percentage

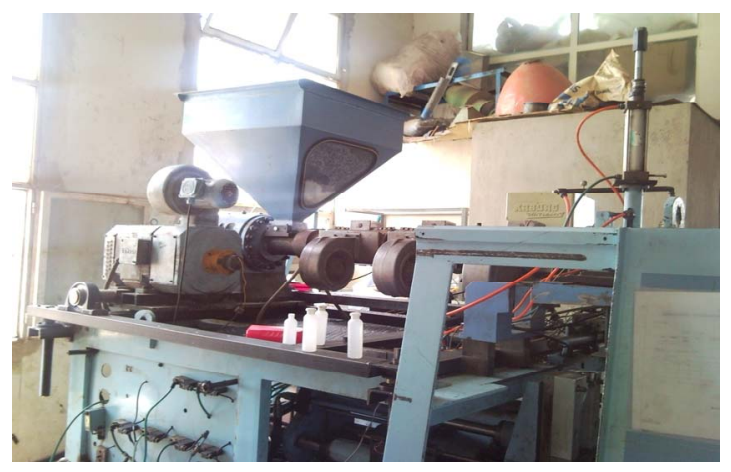

Figure 15. The machine after a modification.

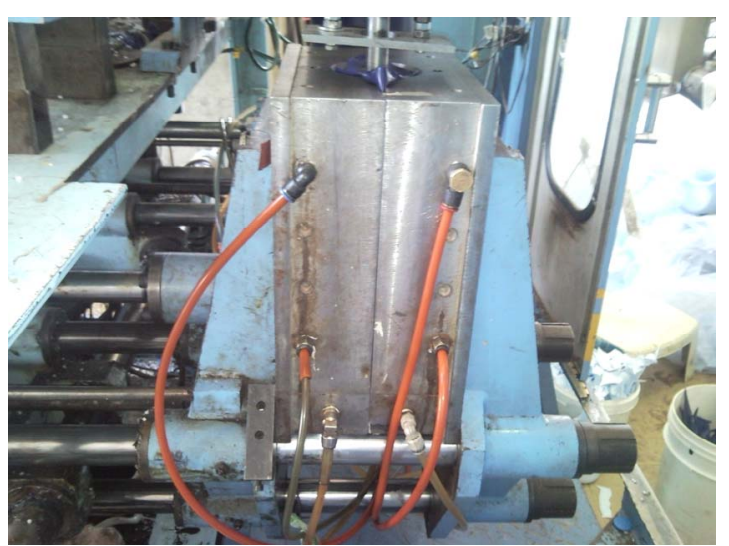

Figure 16. The machine after the modification of (station).

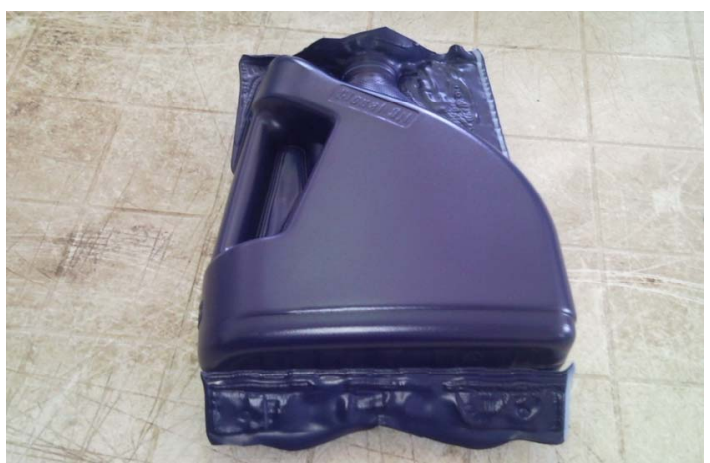

Figure 17. The newly produced 5-litre containers.

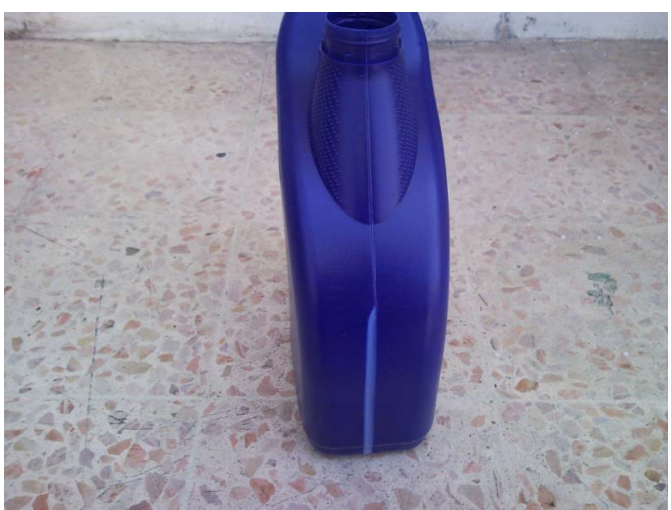

Figure 18. The newly produced 5 -litre containers with the translucent view strip.

of the crushed material was $100 \%$. However, the situation differs with containers prepared for food items in this case, milled materials are not advised.

The study found that the milling cost is remarkably low, around 5\% only, and attributed to the electrical energy consumption in the milling operations and machine maintenance. Given that the cost of the milled material is half of the raw material on the local market, then it is quite recognizable that the saving in production cost will approximately comes closer to $50 \%$.

\section{The Economic Feasibility}

For example, some economic account can be made of a 4-litre container, the container needs 200 grams of raw material, while the recycled material weighs 40 grams. So, if the factory produces 3000 containers per day in 26 working days a month, then the gross production in 6 months needs $93,600 \mathrm{~kg}$ of raw material, whereas recycling will weigh only $18,720 \mathrm{~kg}$ (which was not taken into account in the past). Hence, the raw material that should be bought is $74,880 \mathrm{~kg}$, taking into consideration that the allowed mix in this kind of production is $100 \%$ (Opaque containers), and the purchase value of this recycled material is only half cost of the raw material (JD 1000 vs. 500). Thus the total cost of the material to be 


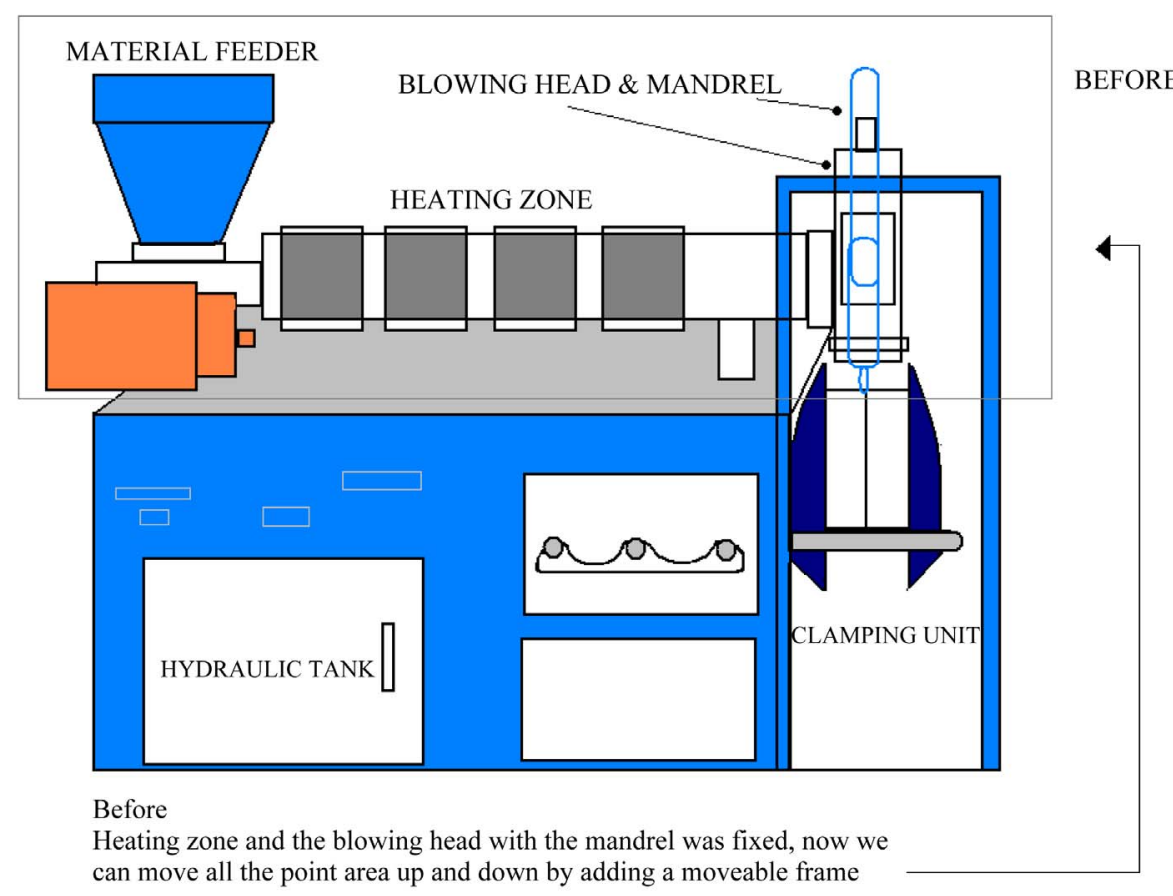

Figure 19. The top part of the machine before the modifications.

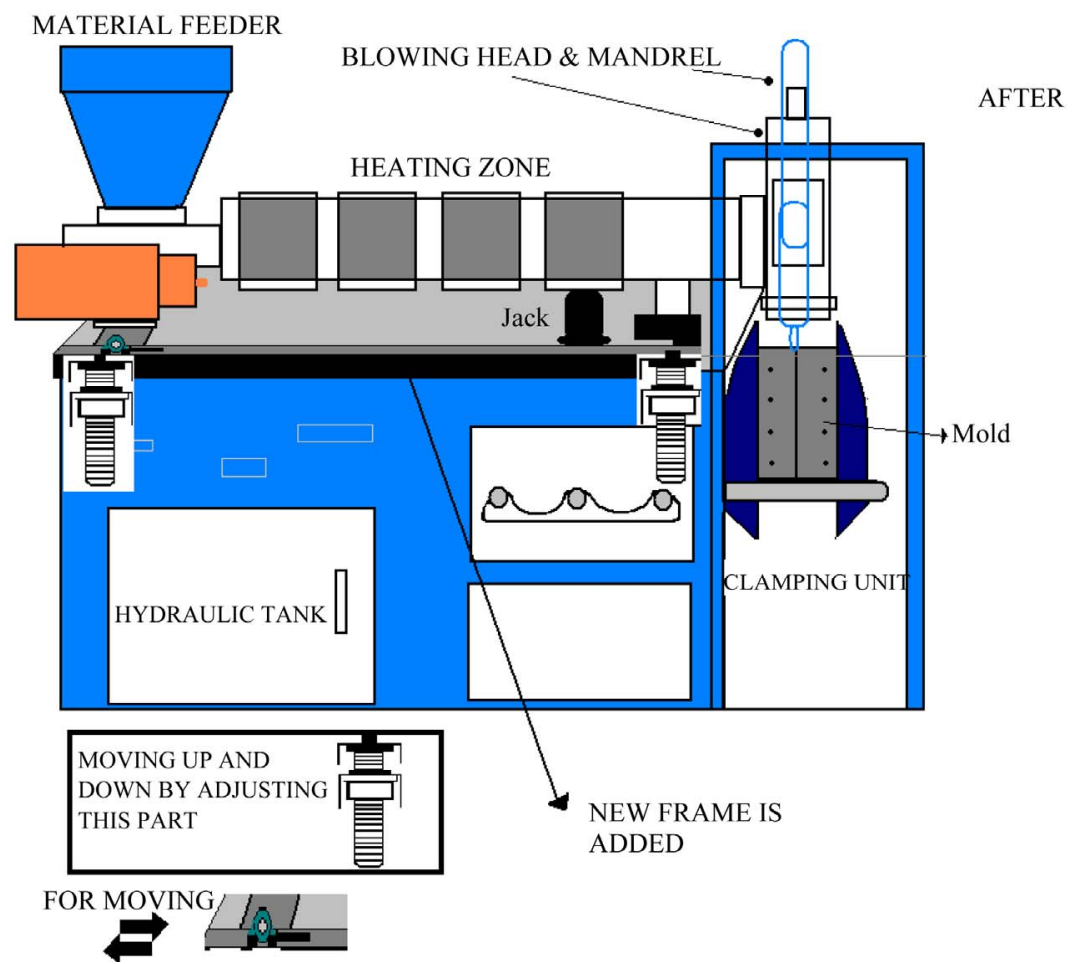

Figure 20. The top part of the machine after the modifications.

purchased is 37,440 Jordanian dinars [JD]. Accordingly, saving in this kind of production would amount to $60 \%$. Table 1 shows the difference in saving in the abovementioned case and that of producing light (natural) containers, given that the allowed mix in this case is $50 \%$.
As shown by the table, saving will, indeed, be $35 \%$ in case containers were produced in the same period of the year, i.e. 6 months, whereas it will be $47.5 \%(0.6+$ $0.35) / 2$ in this case. It is therefore estimated that the average saving ratio will approximately come closer to $50 \%$. 
Table 1. Shows the economic feasibility.

\begin{tabular}{|c|c|c|c|c|c|c|}
\hline & $\begin{array}{c}\text { Ratio of Maxing } \\
\text { A }\end{array}$ & $\begin{array}{c}\text { Gross Production } \\
\text { Needs in }[\mathrm{kg}] \\
\text { B }\end{array}$ & $\begin{array}{c}\text { From Recycle } \\
\text { Saving }[\mathrm{kg}] \\
\mathrm{C} \\
\end{array}$ & $\begin{array}{l}\text { Quantity of Purchased } \\
\qquad D=(B \cdot A-C)\end{array}$ & $\begin{array}{l}\text { Saving Value [J.D] } \\
\text { E }\end{array}$ & $\begin{array}{c}\text { Saving Ratio } \\
\mathrm{F}=(\mathrm{B} \cdot \mathrm{A}-\mathrm{E}) / \mathrm{B}\end{array}$ \\
\hline Opaque containers & $100 \%$ & 93,600 & 18,720 & 74,880 & 37,440 & 0.6 \\
\hline Natural containers & $50 \%$ & 93,600 & 18,720 & 28,080 & 14,040 & 0.35 \\
\hline Food stuffs containers & \multicolumn{6}{|c|}{ The factory doesn't product this type of containers } \\
\hline
\end{tabular}

\section{Conclusion}

The machine modification constitutes a qualitative move in the factory. Compared to the high purchasing price of a new machine, the cost of the old machine's development is rather low. Moreover, the qualitative improvement of the produce has promoted the factory's stature, let alone the remarkable reduction in the product's cost. Added to that, there are some positive advantages like reducing the waste to zero point, raising the production's efficiency as a result of new technology. In addition the modifications allow using new desired plastic materials (HDPE) instead of PVC.

\section{Acknowledgements}

The author would like to thank the national program of Faculty for Factory (FFF), and the Fund for Enterprise Support for the financial support in conducting this study.

\section{REFERENCES}

[1] A. K. Wood and R. Rasid, "Effect of Process Variable on Melt Velocity Profile in Extrusion Process Using Single Screw Plastics Extruder," Plastic Rubber and Composites, Vol. 32, No. 5, 2003, pp. 193-198. doi: $10.1179 / 146580103225002722$

[2] R. J. Crawford, "Plastics Engineering," 3rd Edition, Butterwort-Heinemann, Oxford, 1998.

[3] C. Rauwendaal, "Polymer Extrusion," 3rd Revised Edition, Hanser Grander Publisher, New-York, 1994.

[4] R. Alavi, S. A. Torabi Angaji and M. Z. Gholami, "Twin-
Screw Extruder and Effective Parameters on the HDPE Extrusion Process," Proceedings of World Academy of Science, Engineering and Technology, Vol. 37, 2009, pp. 204-207.

[5] C. P. Yu and J. M. Roësset, "Dynamic Analysis of Frames Using Continuous Dynamic Stiffness Matrix," Tamkang Journal of Science and Engineering, Vol. 4, No. 4, 2001, pp. 37-45.

[6] C. Prabodh Bolur, "Extrusion of Thermoplastics," Technical papers, 1998. http:/bolur.plastasia.com

[7] N. Domingues, A. Gaspar-Cunha and J. A. Covas, "Computational and Experimental Study of Mixing in a Single Screw Extruder," 10th ESAFORM Conference on Material Forming, American Institute of Physics 2007, Zaragoza, 18-20 April 2007, pp. 867-872.

[8] T. Rydzkowski and G. Radomski, "Mixing Ratios Obtained Using Screw Disc and Screw Extruders, and Selected Properties of Mixture of Reglanulate and Original Material," Plastics, Rubber and Composites, Vol. 37, No. 8, 2008, pp. 376-380. doi: $10.1179 / 174328908 \times 356473$

[9] J. Qu, B. Xu, G. Jin, H. He and X. Peng, "Experimental Studies and Mathematical Modeling of Melt-Pulsed Conveying in Screw Extruders," Polymer-Plastics Technology and Engineering, Vol. 45, No. 10, 2006, pp. 11371142. doi: $10.1080 / 03602550600887228$

[10] A. Thomas Shapler, "Accumulator Head for Producing a Storage Drum with View Stripe," US Patent 4,802,833, 1989.

[11] M. Hirschberger, "Extrusion Head with Adjustable View Stripe Positioning," US Patent 5,221,540, 1993.

[12] A. Thomas Shapler, R. Thomas Buehler and M. Hirschberger, "Apparatus for Forming a Parison with a View Stripe,” US Patent 4,890,994, 1990. 